\title{
EXPERIMENTAL VERIFICATION OF RAILWAY SUBSTRUCTURE WITH APPLICATION OF REINFORCED GEOCOMPOSITE
}

In the paper the authors present results of experimental measurements realized in a testing stand which was built for evaluation of reinforced effect of geocomposite MACRIT GTV/50-50 B applied into a railway substructure. Methodology of experimental measurements, observed physical characteristics of used grounds and results of static loading tests for various granularity and thickness of subbase material $(150 \mathrm{~mm}-600 \mathrm{~mm}$ ) are described. The main result of the experimental evaluation of two-tested subbase materials is a proposal of nomograms for dimensioning the railway substructure with application of topical geosynthetic material.

\section{Introduction}

Modernization of the main basic railway of the Slovak Railways (ŽSR) that belong to the Trans-European corridors and expected higher loadings for axle and railway speeds require essentially higher demands not only for an excellent condition of railway superstructure, but for railway substructure, too. It is common knowledge that the long-time reliable spreading of the train set loading, which affects throughout the rail, railway bed and subbase to the subgrade surface without permanent cracks of the particular construction levels of the sleeper subgrade is a basic assumption of safe and trafficable railway. In the case of insufficient loading capacity of the subgrade surface special deformation problems rise in the railway construction, especially in the railway substructure, which influence the quality and traffic reliability of the railway.

Increase in loading capacity of the railway substructure is possible through various methods, as for example the changing of subgrade surface of small loading capacity with stabilization of surface soils or with the strengthening of sleeper subgrade construction. In the present time geosynthetic reinforced elements, named as reinforced construction layers, application into the railway substructure, have ever more utilizations in the process of increasing the railway substructure loading capacity.

According to the amended annexe No. 2 of Regulation S4 of ŽSR, geosynthetic reinforcement can be applied into the railway substructure body as are, for example: geogrids, geocomposites, geocells, or reinforced geotextiles. The main shortcoming of an objective and effective use of particular geosynthetic materials into the railway substructure is absence of relevant methodology of dimensioning, or nomograms to propose and evaluate the reinforced construction layers of substructure. According to [2], the calculated thickness of a construction layer can be decreased during the application of geosynthetic reinforcement, by about 25\% (if the construction layer consists of material with rounded grains) or by about $30 \%$ (if the used material is crushed), or, according to [3], the cal- culated thickness of a construction layer can be reduced by about $0.10 \mathrm{~m}$ during geosynthetic reinforced element application.

On the author's personal experience, which was gathered during diagnostics of many constructions with geosynthetic materials in construction layers of the railway substructure, the above dispositions are only estimative and are not valid for various combinations of geosynthetic elements and materials of construction substructure. For that reason, an outdoor and internal testing stand was built in the Department of Railway Engineering and Track Management (DRETM), to test various reinforced construction layers from the point of view of their loading capacity and climate resistance, and consequently, to define subbase dimensions to the required value of equivalent deformation module in the level of railway surface.

Further more, in the paper the methodology and up to time results of experimental testing of railway substructure with using geosynthetic reinforced element MACRIT GTV/50-50 B will be presented with various characteristics of construction layer material (subbase layer of different granularity curve) and with respect to constant loading capacity of subgrade surface.

\section{Testing Stand and Methodology of Experimental Measurement}

The experimental measurement of reinforced effect of geosynthetic material MACRIT GTV/50-50 B was realized on the great internal testing stand of DRETM.

The testing stand (Fig. 2.1) has the following dimensions in length $\times$ width $\times$ height: $3400 \mathrm{~mm} \times 1950 \mathrm{~mm} \times 1200 \mathrm{~mm}$. Because of preservation of cross - and lengthwise stand stability, its bottom and walls are reinforced with transversal and vertical angle steel ribcages (reinforcements). In its upper level there is

\footnotetext{
* Libor Ižvolt, Martin Mečár

University of Žilina, Faculty of Civil Engineering, Department of Railway Engineering and Track Management, Komenského 52, 01026 Žilina.

Slovak Republic, Tel: +421-41-7634818, E-mail: libori@fstav.utc.sk, mecar@fstav.utc.sk
} 

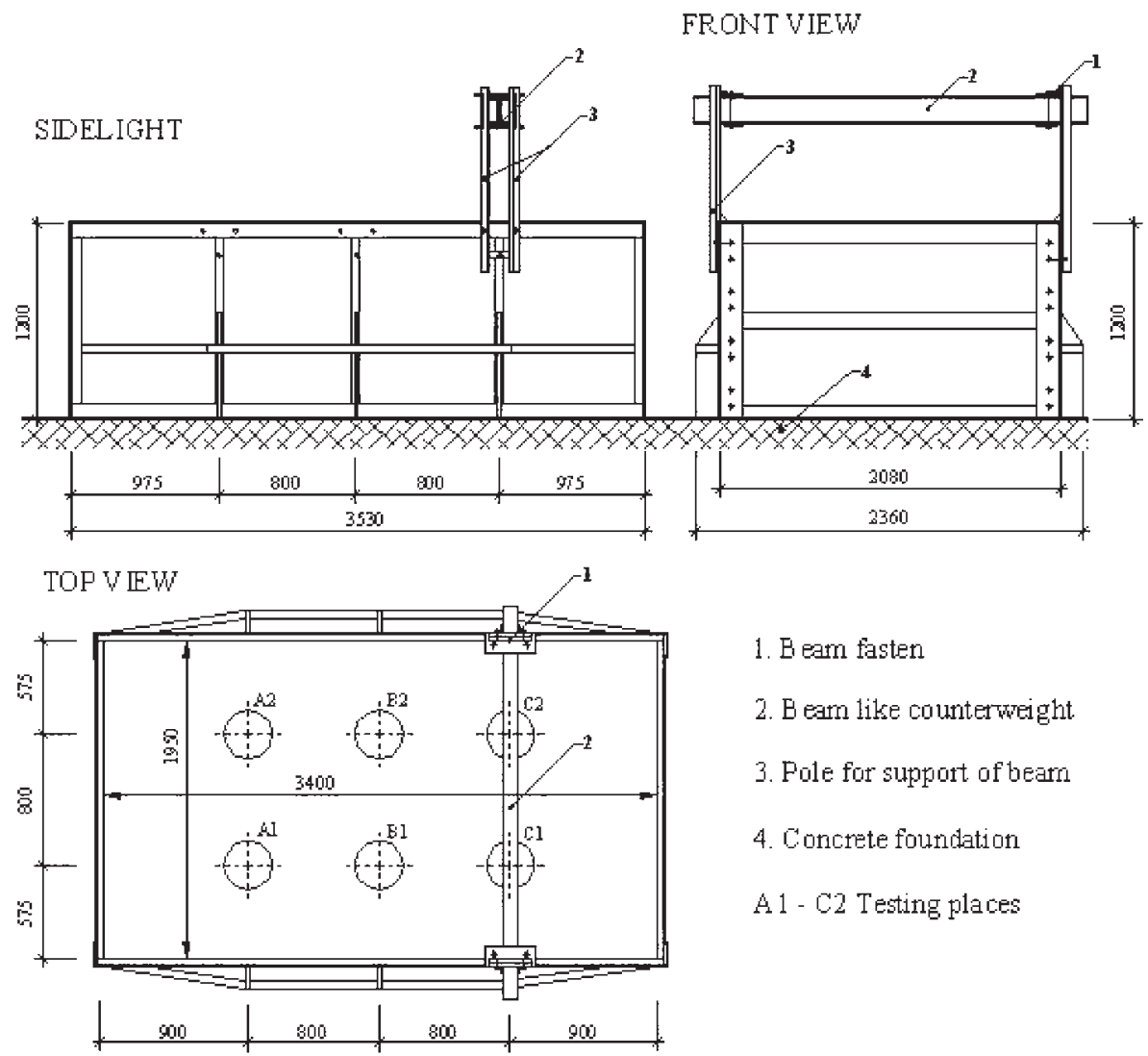

1. Bi eam fasten

2. B ean like counterweight

3. Fole for support of bearn

4. Concrete founclation

A1- C2 Testing places

Fig. 2.1 Testing stand of DRETM

a steel beam which can be fixed in three positions in length of the stand and which acts as counterweight during static loading tests

The testing stand is fulfilled with soil, up to the height of $600 \mathrm{~mm}$, which is characterized as sandy clay (the results from soil laboratory tests are described in chapter 4) according to the granularity analysis. The average value of static deformation module $E_{0}$ for experimental measurements was about $7 \mathrm{MPa}$ before building the particularly layers and about 9,5 MPa after taking off the whole material of subbase construction.

Before the subbase building maximal and minimal volume weight for broken sand was found out (to determine the compaction criterion, formulated via relative lying down $I_{D}$ according to the Slovak Technical Standard STN 72 1018) and necessary heightening before the compaction so that the required thickness of subbase would be kept. Decreases after compaction were found out with a special experiment done in the bin of $305 \mathrm{~mm}$ in diameter for the subbase thickness after compaction 100 and $150 \mathrm{~mm}$.

Further building of the tested construction continueed as follows:

- Bedding, tightening and fixation of geosynthetic material MACRIT GTV/50-50 B on the subgrade surface in the edge of stand with steel pike.
- Bringing subbase material into the calculated height to have layers of thickness of 150, 300, 450 or $600 \mathrm{~mm}$ (measured with levelling) after compaction with vibrating-plate-compactor ViDo $25 / 40$ to the required compaction criterion.

- Gradual working in each particular layer:

- 6 static loading tests.

- 15 dynamic tests before and 15 after static plate loading tests (in places around $\boldsymbol{A}_{1}, \boldsymbol{A}_{2}, \boldsymbol{B}_{1}, \boldsymbol{B}_{2}, \boldsymbol{C}_{1}, \boldsymbol{C}_{2}$, position).

- 3 tests of volume weight with the hole method in the positions where static loading tests were done.

- Determination of humidity and swept away elements of subbase material.

No compacted sheet of material with thickness of about $150 \mathrm{~mm}$ was left near the stand walls, to eliminate the influence of rigid stand walls. After realization of all the above measurements, the subbase material was taken off and control tests of loading capacity of subgrade surface were done.

\section{Methodology of Finding the Deformation Characteristics Out}

Deformation characteristics of evaluated construction layers of railway substructure and subgrade surface were found out with a static loading test and with a dynamic loading test for control, 
with convention with amended annexes No. 20 of regulation [4] The compaction quality of built-in materials was found out according to the regulation [4].

The process of the static loading test consists of the following activities:

- The surface of tested layer is compound with dry fine-grained siliceous sand to fill in surface unevenness.

- A solid circle board with diameter of $d=300 \mathrm{~mm}$ is embedded up to the treated surface.

- To a spherical hinge of loading board is embedded hydraulic system consisting of ahydraulic lifter ENERPAC model RC-59 with maximal imply force of $50 \mathrm{kN}$, a manually controlled hydraulic pump - ENERPAC model P-142, with the maximal imply liquid pressure $70 \mathrm{MPa}$, a manometer $B G F-168 S R$ with a range of $0-50 \mathrm{kN}$ with the least scale division of $0.1 \mathrm{MPa}$ and a hydraulic compressive hose with the length of $2.5 \mathrm{~m}$.

- The hydraulic lifter stretches on a steel beam, which was fixed in three points lengthwise the testing stand.

The loading capacity of particular layers of the tested railway substructure and subgrade surface was measured with static loading tests, done in 2 loading cycles with equipment in fig. 3.1. The main loading levels $0,25,50,75$ and $100 \mathrm{kPa}$ and unloading levels 75 , 50,25 and $0 \mathrm{kPa}$ were chosen to find the loading capacity of the subgrade surface in both cycles. In case of testing subbase material the following loading levelswere chosen: $0,50,100,150,200 \mathrm{kPa}$ and unloading was done in levels: $150,100,50$ and $0 \mathrm{kPa}$.

For each loading level, the value of deformation was read after a compaction consolidation via 3 digital sensors MITUTOYO, placed regularly into a triangle in the edge of the solid circle board. From such readings the following was determined:

- Static transform module $E_{0}$,

- Static deformation module $E_{d e f 1}$ and $E_{d e f 2}$

The static transform module $E_{o}$ is characterized according to the [1] with the equation:

$$
E_{0}=\frac{1.5 \cdot p \cdot r}{y} \quad[\mathrm{MPa}]
$$

where $p \quad$ is the specific pressure to the loading board (0.1 MPa, or $0.2 \mathrm{MPa}$ ),

$r$ is the radius of loading board in meters $(0.15 \mathrm{~m})$,

$y$ is the whole average pressure of loading board in meters, in the second loading cycle,

1.5 is the constant considering the surrounding patterns and actions, which are necessary during loading with circle board.

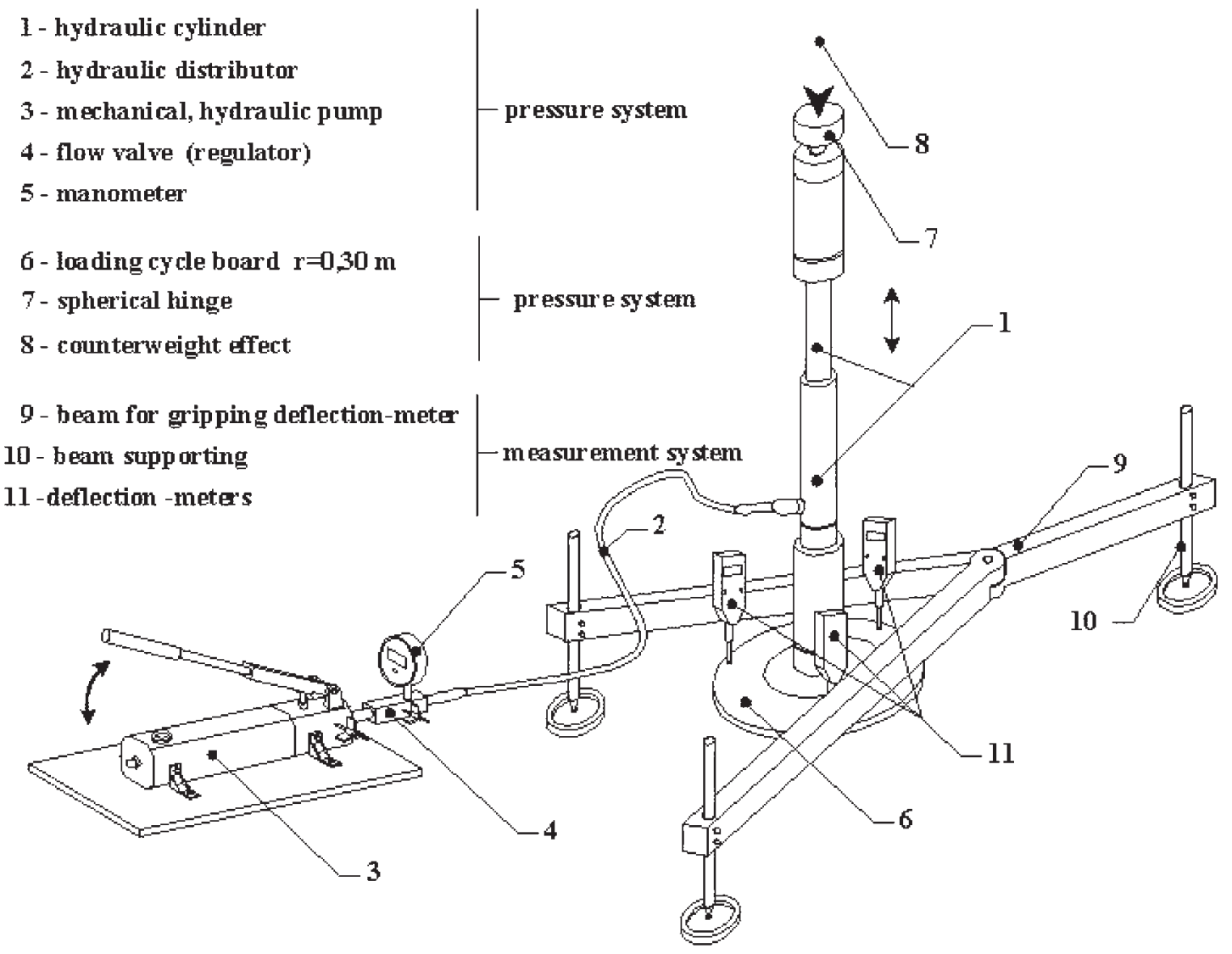

Fig. 3.1 Equipment for finding out the static transform module 
Figure 3.2 shows the principle of determining the transform module with using two loading cycles.

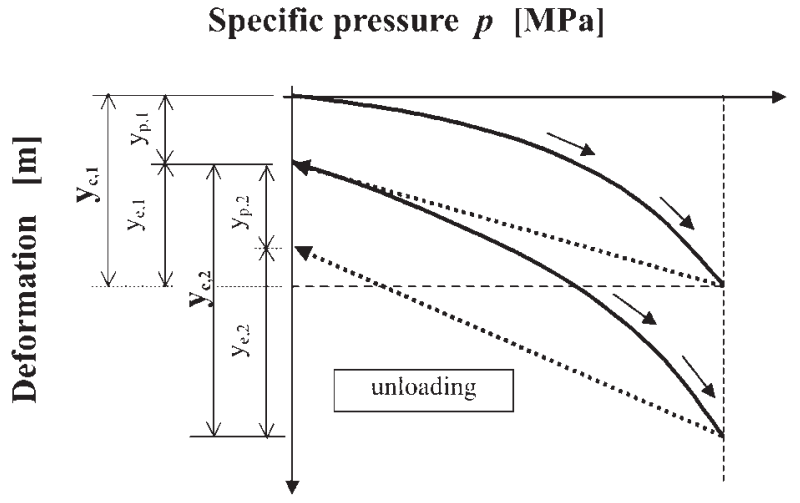

Fig. 3.2 Principle of the deformation modulus calculation

The deformation module $E_{01}$ was determined from the first loading test and $E_{02}$ from the second one. Compaction was considered to be adequate when the proportion of both of deformation modules for subbase reached the value $E_{02} / E_{01} \leq 2.2$ and for subgrade surface $E_{02} / E_{01} \leq 2.5$. The range of compaction work was chosen so that the reached values were similar to those in situ (according to the experience they are by $10-20 \%$ higher than the minimal required values).

\section{Characteristics of Built-in Materials in Testing Stand}

Physical characteristics of composite soil and subbase material were necessary to identify for evaluation of reinforcing effect of geosynthetic MACRIT GTV/50-50 B. Physical characteristics of materials used for the tested construction of railway substructure that was placed on a large testing internal stand were evaluated in the laboratory of DRETM separately for subgrade surface material and for subbase material.

\subsection{Description of Reinforced Geosynthetic MACRIT GTV/50-50 B}

Geosynthetic material MACRIT GTV/50-50 B (Fig. 4.1) is a polystyrene geocomposite, compound with non-woven geotextile (ensures separating and filtrating function) and reinforced geogrid ARTER. Geotextile protects geogrid before damage when the cover layers are built-in and compacted and so it brings higher assurance during geocomposite building-in. The reinforced effect of geogrid ARTER is reached thanks to directionality Oriented Structure (D.O.S) that causes that the reinforced fibres have been straighten already during production.

Technical parameters of geocomposite MACRIT GTV/50-50 B:

- Pulling force (longitudinal/transversal) 50/50.

- Elongation (longitudinal/transversal) [\%] 12/12.
- Pulling force during $2 \%$ elongation $[\mathrm{kN} / \mathrm{m}] \quad 11 / 12$.

- Pulling force during $3 \%$ elongation $[\mathrm{kN} / \mathrm{m}] \quad 15 / 16$.

- Pulling force during $5 \%$ elongation $[\mathrm{kN} / \mathrm{m}] \quad 27 / 27$.

- Basic weight $\left[\mathrm{g} / \mathrm{m}^{2}\right] \quad 500$.

- Maximal width [m] 100

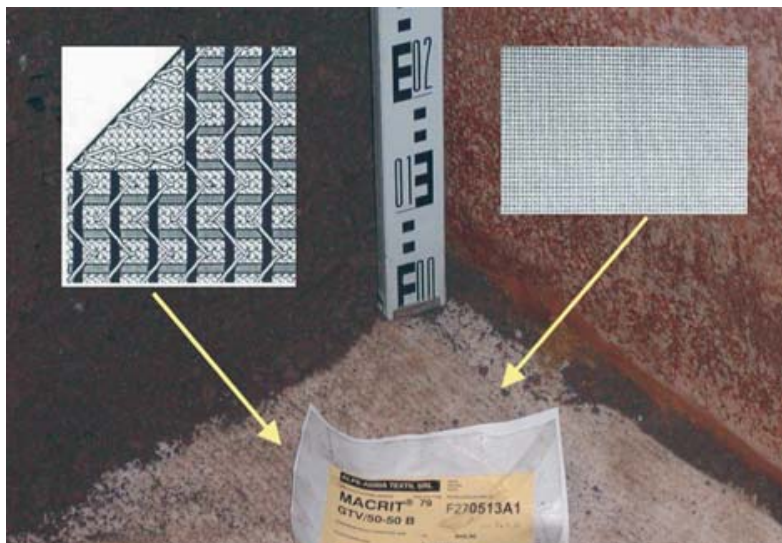

Fig. 4.1 View on the arrangement and structure of geocomposite MACRIT GTV/50-50 B

\subsection{Subgrade Surface}

Soil from the locality Žilina - Solinky was applied for the subgrade surface to reach the required bearing capacity of about $7 \mathrm{MPa}$. The soil samples from subgrade surface of the testing stand were brought from the localities where the static loading stands are.

For soil classification according to the USCD system we have to make a granularity analysis to find out the Atterberger limits: humidity in the yield limit $w_{L}$, humidity in the plastic limit $w_{P}$ and plastic index $I_{P}$. Laboratory evaluation of samples granularity composition was done according to [5]. Atterberger limits were calculated according to [7] and [8] and humidity according to [6]. These tests were adjusted via the software SOILAB.

On the base of the above laboratory results, soil was classified in terms of [9] as sandy clay with symbol $F_{4}=C S$. Further characteristics of subgrade surface soil:

- Humidity in the plastic limit $w_{P}[\%] \quad 14.9$.

- Humidity in the yield limit $w_{L}[\%] \quad 41.9$.

- Humidity $w[\%] \quad 22.0$

- Volume weight of humid soil $\rho\left[\mathrm{kg} / \mathrm{m}^{3}\right] \quad 2081.0$.

- Volume weight of dry soil $\rho_{d}\left[\mathrm{~kg} / \mathrm{m}^{3}\right] \quad 1707.0$.

\subsection{Subbase}

Broken stone of fraction 0-32 mm was used to build-in subbase of the tested railway substructure. In the first phase of the experimental measurements the subbase material conforms from the view of its granularity [9] and in the second phase we admixed to the previous material $30 \%$ of broken stone weight of fraction 


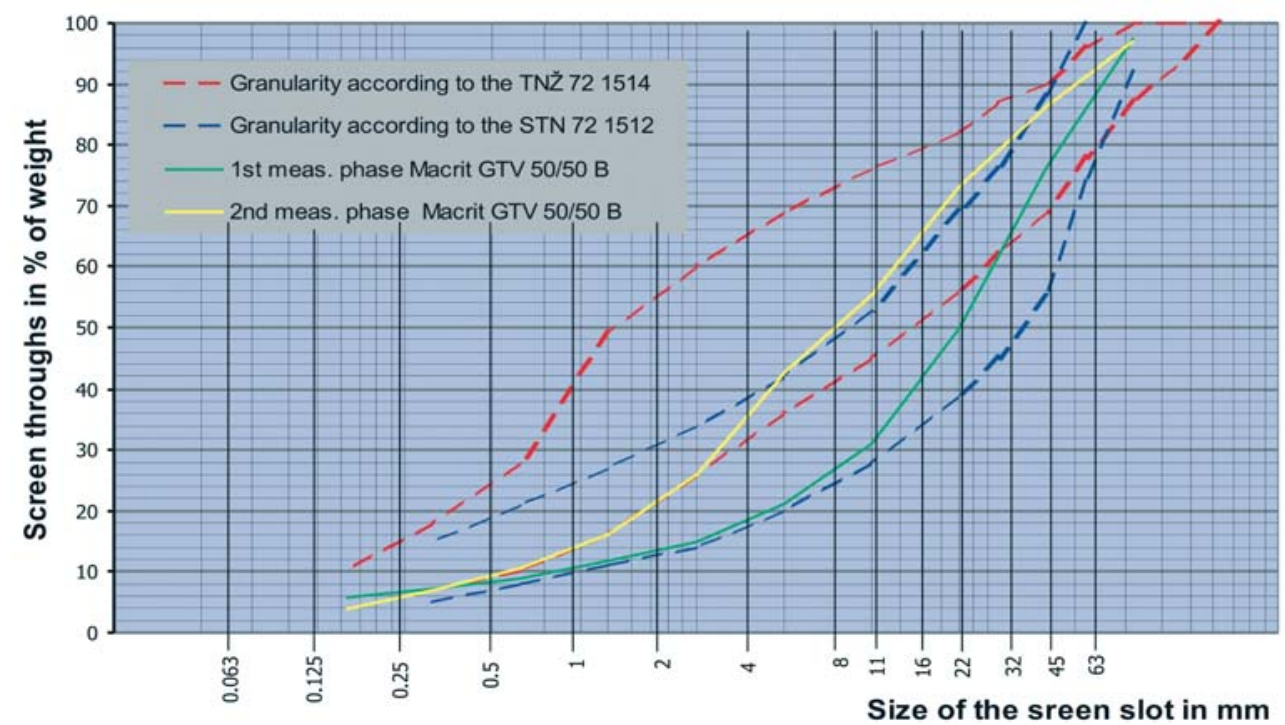

Fig. 4.2 Granularity curves of subbase material

0-4 $\mathrm{mm}$. This mix material conformed the required demands concerning to the granularity curve in subbases according to [10].

The granularity curves of material applied into subbase of the tested railway substructures are presented in figure 4.2 with required granularity limits presented in [9] and [10].

On the base of granularity analysis soil was classified as gravel with good granularity with symbol $G 1=G W$.

Before the experimental measurements we measured granularity, minimal volume weight $\rho_{\text {dmin }}$, maximal volume weight $\rho_{\text {dmax }}$, number unequal-granularity $C_{u}$ and number of curvature $C_{c}$ in the subbase material. In the process of subbase building, we took from each particularly tested construction layer 3 samples to determine the volume weight of humid ground $\rho$, the volume weight of ground after dry out $\rho_{d}$, humidity $w$ wash-away elements and relative settlement $I_{D}$.

The complex outline of reached results from the samples taken from particular layers of the tested subbase that were calculated according to the demands described in [10] is shown in tables 4.1 and 4.2 .

\section{Evaluation of Loading Tests and Proposal of Nomograms for Dimensioning of reinforced Subbase}

In table 1, there are average values of static transform module during applying the reinforced geocomposite MACRIT GTV/50$50 \mathrm{~B}$ in particular layers of subbase (layers divided according to the
Outline of measured parameters of subbase material - 1st phase

\begin{tabular}{|c|c|c|c|c|}
\hline $\begin{array}{c}\text { Characteristics of material / } \\
\text { construction thickness }\end{array}$ & $0.150 \mathrm{~m}$ & $0.300 \mathrm{~m}$ & $0.450 \mathrm{~m}$ & $0.600 \mathrm{~m}$ \\
\hline $\begin{array}{l}\text { Minimum bulk density } \\
\rho_{d},{ }_{\text {min }}\left[\mathrm{kg} \cdot \mathrm{m}^{-3}\right]\end{array}$ & \multicolumn{4}{|c|}{1635} \\
\hline $\begin{array}{l}\text { Maximal bulk density } \\
\rho_{d}, \text { max } \\
{\left[\mathrm{kg} \cdot \mathrm{m}^{-3}\right]}\end{array}$ & \multicolumn{4}{|c|}{2156} \\
\hline $\begin{array}{l}\text { Bulk density of of soil } \\
\rho\left[\mathrm{kg} \cdot \mathrm{m}^{-3}\right]\end{array}$ & 2087 & 2140 & 2181 & 2204 \\
\hline $\begin{array}{l}\text { Dry bulk density of soil } \\
\rho_{d}\left[\mathrm{~kg} \cdot \mathrm{m}^{-3}\right]\end{array}$ & 2030 & 2083 & 2128 & 2130 \\
\hline Moisture $w[\%]$ & 2.8 & 2.7 & 2.5 & 3.5 \\
\hline Wash-away elements & 5.65 & 5.31 & 5.37 & 5.66 \\
\hline Relative density $I_{D}$ & 0.81 & 0.89 & 0.96 & 0.96 \\
\hline Coefficient of uniformity $C_{u}$ & \multicolumn{4}{|c|}{$>15$} \\
\hline Coefficient of curvature $C_{c}$ & \multicolumn{4}{|c|}{$>1$} \\
\hline
\end{tabular}

Tab. 4.1 Outline of measured parameters of subbase material - 2nd phase

\begin{tabular}{|c|c|c|c|c|}
\hline $\begin{array}{c}\text { Characteristics of material / } \\
\text { construction thickness }\end{array}$ & $0.150 \mathrm{~m}$ & $0.300 \mathrm{~m}$ & $0.450 \mathrm{~m}$ & $0.600 \mathrm{~m}$ \\
\hline $\begin{array}{l}\text { Minimum bulk density } \\
\rho_{d},{ }_{\text {min }}\left[\mathrm{kg} \cdot \mathrm{m}^{-3}\right]\end{array}$ & \multicolumn{4}{|c|}{1504} \\
\hline $\begin{array}{l}\text { Maximal bulk density } \\
\rho_{d}, \text { max } \\
\left.\text { kg.m } \mathrm{m}^{-3}\right]\end{array}$ & \multicolumn{4}{|c|}{2047} \\
\hline $\begin{array}{l}\text { Bulk density of of soil } \\
\rho\left[\mathrm{kg} \cdot \mathrm{m}^{-3}\right]\end{array}$ & 2023 & 2065 & 2017 & 1986 \\
\hline $\begin{array}{l}\text { Dry bulk density of soil } \\
\rho_{d}\left[\mathrm{~kg} \cdot \mathrm{m}^{-3}\right]\end{array}$ & 1950 & 1996 & 1955 & 1922 \\
\hline Moisture $w[\%]$ & 3.7 & 3.5 & 3.1 & 3.4 \\
\hline Wash-away elements & 5.92 & 5.89 & 6.70 & 5.63 \\
\hline Relative density $I_{D}$ & 0.86 & 0.93 & 0.87 & 0.82 \\
\hline Coefficient of uniformity $C_{u}$ & \multicolumn{4}{|c|}{$>15$} \\
\hline Coefficient of curvature $C_{c}$ & \multicolumn{4}{|c|}{$>1$} \\
\hline
\end{tabular}


broken stone of fraction $0-32 \mathrm{~mm}$ ) of both tested constructions The values of static transform module in particular construction layers of subbase are defined as an average value from 6 results of static loading tests that were done in the following places (see figure 2.1): $A_{1}, A_{2}, B_{1}, B_{2}, C_{1}, C_{2}$.

On the base of results of static loading tests which were done on the big internal testing stand of DRETM it is possible to determine progress of static transform module. Figure 5.1 represents the proposal of nomogram for dimensioning the railway substructure for the following construction:

- Subgrade surfaces about $7 \mathrm{MPa}$.

- Geocomposite MACRIT GTV/50-50 B.

- Subbase is broken stone of fraction $0-32 \mathrm{~mm}$ with two various granularity curves of graded thickness from $150 \mathrm{~mm}$ to $600 \mathrm{~mm}$.

To compare reinforced and non reinforced railway substructure we used methodology shown in annex No. 21 regulation [1]

Average values of static deformation modulus

Tab. 5.1 during applying reinforced geocomposite MACRIT GTV/50-50 B in the particular subbase layers of fraction 0-32 $\mathrm{mm}$.

\begin{tabular}{|l|c|c|}
\hline Description of tested place & \multicolumn{2}{|c|}{ Static deformation modulus $E_{0}[\mathrm{MPa}]$} \\
\cline { 2 - 3 } & $\begin{array}{c}\text { 1st phase } \\
\text { (Curve of subbase } \\
\text { material grain-size } \\
\text { complains to } \\
\text { STN 73 1001) }\end{array}$ & $\begin{array}{c}\text { 2nd phase } \\
\text { (Curve of subbase } \\
\text { material grain-size } \\
\text { complains to } \\
\text { TNŽ 72 1514) }\end{array}$ \\
\hline Subgrade surface & 7 & 7 \\
\hline Subbase of thickness $0.150 \mathrm{~m}$ & 14 & 17 \\
\hline Subbase of thickness $0.300 \mathrm{~m}$ & 37 & 33 \\
\hline Subbase of thickness $0.450 \mathrm{~m}$ & 62 & 55 \\
\hline Subbase of thickness $0.600 \mathrm{~m}$ & 80 & 62 \\
\hline
\end{tabular}

that represents the basic methodology for designers. Using this information we reached following values of bearing capacity expressed with the equivalent transform modules $E_{e 1}$ to $E_{e 4}$ on the particular construction layers of subbase and in the level of subbase surface without built-in geosynthetic element (tab. 5.2):

\section{Contribution}

Two phases of experimental measurements that were realized in the railway substructure with built in reinforced geocomposite MACRIT GTV/50-50 B bring results on the basis of which we can confirm not only the expected effect of used geosynthetic but also the influence of chosen subbase material on the resulted bearing capacity of the whole railway substructure.

Lower values of the equivalent transform module on the particular subbase surfaces in the second phase of experimental measurements (in about 12 till 30\%) were predicted because of granularity as subbase material required in [10] a has higher proportion of fine fraction $0-2 \mathrm{~mm}$ (nearly $70 \%$ ) in comparison with granularity defined in [9] (about 42\%). This higher proportion of fine fraction causes lower permeability of the built in subbase, but we reach higher bearing capacity. However there is higher danger that a high proportion of fine fraction increases the ability of crushed

Equivalent deformation modulus $E_{i}[\mathrm{MPa}]$ determined according to the methodology of regulation [1], annex No. 21.

\begin{tabular}{|l|c|c|c|c|}
\hline $\begin{array}{l}\text { Thickness of subbase } h_{i} \\
\text { /static deformation modulus } \\
\text { of subbase } E_{i}[\mathrm{MPa}]\end{array}$ & $\begin{array}{c}h_{1}= \\
0.150 \mathrm{~m}\end{array}$ & $\begin{array}{c}h_{2}= \\
0.300 \mathrm{~m}\end{array}$ & $\begin{array}{c}h_{3}= \\
0.450 \mathrm{~m}\end{array}$ & $\begin{array}{c}h_{4}= \\
0.600 \mathrm{~m}\end{array}$ \\
\hline Minimum $E_{1}=60 \mathrm{MPa}$ & 15 & 23 & 28 & 32 \\
\hline Maximum $E_{2}=80 \mathrm{MPa}$ & 17 & 27 & 34 & 40 \\
\hline
\end{tabular}

Progress of static modul of deformation of the construction: MACRIT GTV/50-50 B + subbase of broken stone with fraction 0-32 mm

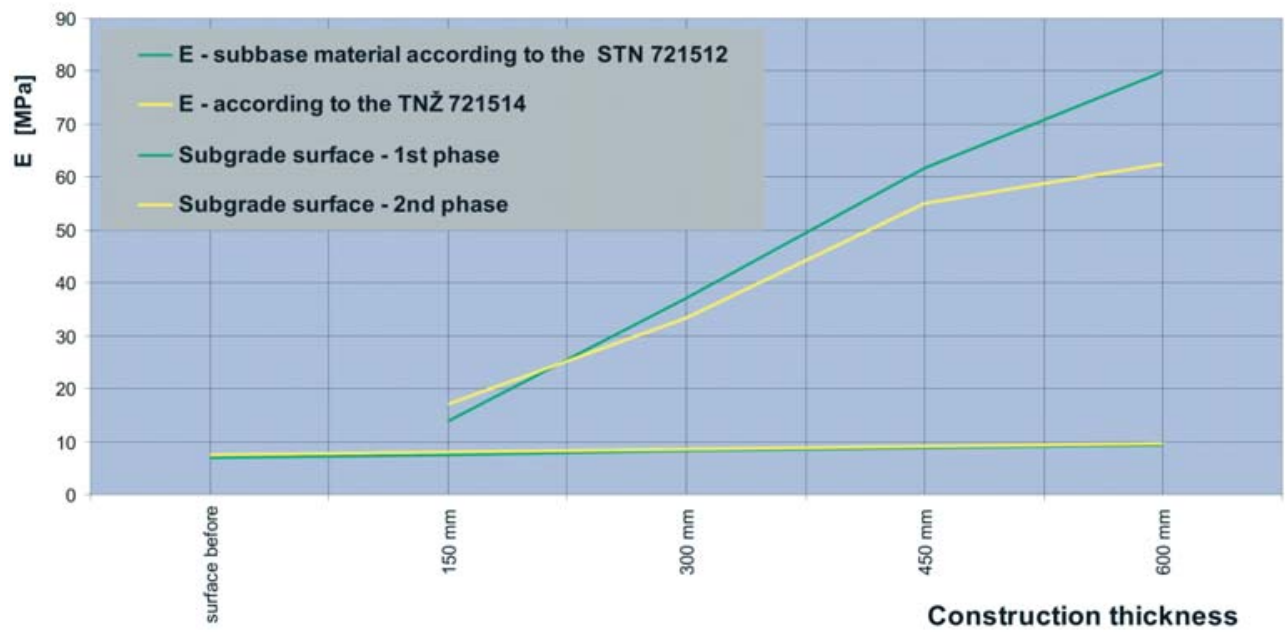

Fig. 5.1 Progress of static transform module for construction with geocomposite MACRIT GTV/50-50 B 
material to keep the humidity and so that frost susceptibility will show primary and secondary frost effects.

When comparing both values of the equivalent static deformation module, which were determined according to the regulation S4, annex No. 21 and values reached in experimental verification of the railway substructure with geocomposite MACRIT GTV/50 $50 \mathrm{~B}$ (see tab. 5.1 and 5.2) we can confirm its reinforced effect. The difference between the calculated value of non-reinforced and reinforced tested construction moves in the first phase of experimental measurements from about $160 \%$ to about $250 \%$ and in the second phase from about $140 \%$ to about $200 \%$, under consideration of the transform module of subbase material $E_{1}=60 \mathrm{MPa}$ and its graded thickness from $150 \mathrm{~mm}$ to $600 \mathrm{~mm}$. When considering the transform module of subbase material $E_{1}=80 \mathrm{MPa}$, the difference in the first phase of experiment is from about $140 \%$ to $200 \%$ and in the second phase from about $120 \%$ to $160 \%$.
When thickness of the subbase construction was smaller than 0.150 m, reinforced effect of geocomposite MACRIT GTV/50-50 B was not remarkable either in both phases of measurements. Other evaluated results allow assuming the availability of geocomposite MACRIT GTV/50-50 B, like geosynthetic material, for applying in such technology aimed to increase the bearing capacity of the railway substructure in the Slovak Railways. However, one question is open: behaviour of this material during long-time traffic loading.

The authors of the paper would like to thank the grant commission VEGA for supporting the project No. 1/0341/03, which allows the realization of experimental measurements and consequently obtaining the relevant results that are presented in this paper.

\section{References}

[1] Regulation of Slovak Railways (SR) S4: Railway substructure. NADAS Praha, 1988.

[2] Regulation of Czech Railways (CR) S4: Railway substructure. Annex No. 11, 1998.

[3] Richtlinie DB 836 Erdbauwerke planen, bauen und instand halten, modul 0503, 1999.

[4] STN 72 1006: Control of Soils and Bulk Material Compaction.

[5] Technology of laboratory tests in soils and ground mechanics, Czech Geological Office, Praha 1987,

[6] STN 72 1012: Laboratory determination of soil natural moisture.

[7] STN 72 1013: Laboratory determination of plastic limits.

[8] STN 72 1014: Laboratory determination of liquidity limits.

[9] STN 73 1512: Solid gravel for building purposes. Technical demands.

[10] TNŽ 72 1514: Technical and ecological conditions to supply material into construction of track bed and subbase layers. 